\title{
Transcriptome sequencing analysis reveals unique and shared antitumor effects of three statins in pancreatic cancer
}

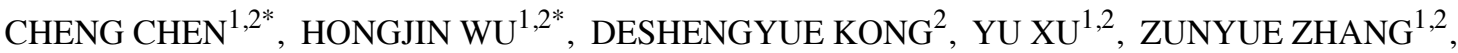

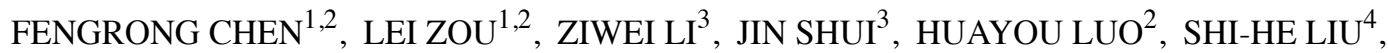 \\ JUEHUA YU ${ }^{1,2,4}$, KUNHUA WANG ${ }^{1,2}$ and F. CHARLES BRUNICARDI ${ }^{4}$ \\ ${ }^{1}$ The NHC Key Laboratory of Drug Addiction Medicine; ${ }^{2}$ Yunnan Institute of Digestive Disease, \\ The First Affiliated Hospital of Kunming Medical University, Kunming, Yunnan 650032; \\ ${ }^{3}$ Shanghai International Travel Healthcare Center, Shanghai 200000, P.R. China; ${ }^{4}$ Department of Surgery, \\ College of Medicine and Life Sciences, University of Toledo, Toledo, OH 43614, USA
}

Received May 6, 2020; Accepted September 15, 2020

DOI: 10.3892/or.2020.7810

\begin{abstract}
Statins, a class of commonly prescribed cholesterol-lowering medications, have been revealed to influence the risk of multiple types of cancer. However, the antitumor effects of statins on pancreatic cancer and their differential efficacy among a variety of statins are not currently well-defined. The aim of the present study was therefore to identify and compare the genes and related biological pathways that were affected by each individual statin on pancreatic cancer. Two human pancreatic cancer cell lines, MiaPaCa2 and PANC1, were exposed to three statins, lovastatin, fluvastatin and simvastatin. The inhibitory effect of statins on pancreatic cancer cell proliferation was first validated. Next, RNA-seq analysis was used to determine the gene expression alterations in either low $(2 \mu \mathrm{M})$ or high $(20 \mu \mathrm{M})$ statin concentration-treated cancer cells. Marked differences in gene transcription profiles of both pancreatic cancer cell lines exposed to high concentration statins were observed. Notably, the high concentration statins significantly suppressed core-gene CCNA2-associated cell cycle and DNA replication pathways and upregulated genes involved in ribosome and autophagy pathways. However, the low concentration statin-induced gene expression alterations were only detected in MiaPaCa2 cells. In conclusion, a marked difference in the intra and inter cell-type performance of pancreatic cancer cells exposed to a variety of statins at
\end{abstract}

Correspondence to: Dr Kunhua Wang or Dr Juehua Yu, The NHC Key Laboratory of Drug Addiction Medicine, The First Affiliated Hospital of Kunming Medical University, 295 Xichang Road, Kunming, Yunnan 650032, P.R. China

E-mail: kunhuawang1@163.com

E-mail: juehuayu@gmail.com

${ }^{*}$ Contributed equally

Key words: statin, lovastatin, fluvastatin, simvastatin, pancreatic cancer, cell cycle, weighted gene co-expression network analysis low or high concentrations was reported herein, which may provide insights for the potential clinical use of statins in future pancreatic cancer therapeutics.

\section{Introduction}

Despite substantial investment and years of research worldwide, pancreatic cancer remains one of the most lethal malignancies with very high mortality rates. For all stages combined, the 1- and 5-year relative survival rates are 27 and $7 \%$, respectively, making it the only type of cancer with an overall 5-year survival rate in the single digits (1). There are currently no effective medications for the treatment of patients with locally advanced or metastatic pancreatic cancer who are ineligible for surgery. The stage at which pancreatic cancer is diagnosed is strongly correlated with overall survival, and the delayed diagnosis results in only $20 \%$ of patients being eligible for surgery or adjuvant therapy (2). Therefore, developing novel and effective drugs is urgently required for this terrible malignancy.

The discovery of new drugs has grown increasingly difficult over the years, as itis a time-consuming, high-investment and high-risk process in traditional drug development. Therefore, drug repurposing has become an increasingly used strategy for identifying novel medications or new uses for approved drugs that have already been optimized for safety and efficacy (3). In the past decade, various high-throughput strategies and experimental platforms have been used for the discovery and identification of repurposable drug candidates, with statins previously identified as potential promising antitumor agents (4). Statins, also known as 3-hydroxy-3-methyglutaryl coenzyme A reductase inhibitors, are some of the most commonly prescribed medications for the treatment of hypercholesterolemia, due to their ability to inhibit de novo cholesterol synthesis, thereby reducing the risk of heart attacks and other major clinical manifestations of coronary artery diseases by up to $37 \%$ (5). In 1987, lovastatin (Mevacor, Altocor and Altoprev) became the first FDA-approved statin. Since then, further statins have been derived and synthesized, including simvastatin (Zocor), atorvastatin (Lipitor and Lipex) 
and fluvastatin (Lescol). In general, statins are safe and well-tolerated by patients, and they all work in a similar way.

In addition to their powerful cholesterol-lowing effects, statins also exert several other cholesterol-independent effects (pleiotropic effects), including improved endothelial function, stabilization of atherosclerotic plaque and anti-inflammatory, antioxidant, anti-proliferative and immunomodulatory effects (6). Notably, there has been growing interest in the potential antitumor effects of multiple statins based on accumulating evidence of their anti-proliferation and anti-inflammatory activities in various types of cancer in a number of preclinical, as well as clinical studies (7). To date, research has indicated that statins may inhibit tumor growth and metastasis through a series of cellular mechanisms, including the promotion of apoptosis, inhibition of cell cycle progression and proliferation, reduction of angiogenesis, and interference with carcinogenesis. For example, lovastatin treatment could cause breast cancer cell death through the LKB1-AMPK-p38MAPK-p53-survivin signaling cascade (8). Recently, simvastatin was reported to attenuate macrophage-mediated gemcitabine resistance of pancreatic cancer by regulating the TGF- $\beta 1 /$ Gfi- 1 axis (9). It has also been shown that the suppression of cholesterol biosynthesis by lovastatin significantly inhibited gallbladder cancer cell proliferation, possibly through the inhibition of DNA repair. However, whether these various statins exert their antitumor function through a consistent mechanism remains largely unknown.

In the present study, a previously established reporter system was used to screen potential drugs for the treatment of pancreatic cancer from the Prestwick Chemical Library $(10,11)$. Three statins were identified: Fluvastatin, lovastatin and simvastatin. Furthermore, low- $(2 \mu \mathrm{M})$ and high-concentration $(20 \mu \mathrm{M})$ treatment with these three statins was used to determine their impact on the global transcriptional activity, as well as their concentration-dependent effect in two human pancreatic cancer cell lines, MiaPaCa2 and PANC1. The aim of the present study was to elucidate the unique and shared functions of these three statins, and thereby gain some insights of theoretical guidance for the potential use of these statins in the future clinical treatment of pancreatic cancer.

\section{Materials and methods}

Materials. In all experiments, pure forms $(\geq 98.0 \%)$ of fluvastatin, lovastatin and simvastatin (Tocris Bioscience) were used. All statins were dissolved in DMSO and tested in final concentrations of 2 and $20 \mu \mathrm{M}$.

Cell culture. Human pancreatic cancer MiaPaCa2 and PANC1 cell lines (American Type Culture Collection) were maintained in DMEM supplemented with $2 \mathrm{mM}$ glutamine, $1 \mathrm{mM}$ Na-pyruvate, 100 units $/ \mathrm{ml}$ penicillin, $100 \mu \mathrm{g} / \mathrm{ml}$ streptomycin and $10 \%$ fetal bovine serum (all from Gibco, Thermo Fisher Scientific, Inc.) at $37^{\circ} \mathrm{C}$ in a humidified atmosphere containing $10 \% \mathrm{CO}_{2}$.

Medium throughput screening of the Prestwick Chemical Library on pancreatic cancer. For preliminary screening purposes, the pancreatic cancer cell line MiaPaCa2bearing stable expressing BIRC5-GLuc was first arrayed in 384-well plates and treated with test compounds at $20 \mu \mathrm{M}$ for $48 \mathrm{~h}$ under serum-free conditions. Changes to the luciferase expression and cell viability were quantitated using the CellTiter-Glo ${ }^{\circledR}$ Luminescent Cell Viability Assay. For more information, the 1,280 chemically and pharmacologically diverse compounds (90\% of which were FDA-approved drugs) from the Prestwick Chemical Library were screened against the pancreatic cancer MiaPaCa2 cell line. Experiments were conducted in 384-well plates. A fully automated Hamilton Star workstation was used for all liquid handling protocols. Compounds were loaded into black F-bottom 384-well assay ready plates (Greiner Bio-One), followed by $200 \mu \mathrm{l}$ of pBIRC5-eGFP, resulting in a final drug concentration of $20 \mu \mathrm{M}$ with $<0.002 \%$ DMSO in the primary screen. Assay plates were cultured for $48 \mathrm{~h}$ in an incubator at $37^{\circ} \mathrm{C}$ in a humidified atmosphere containing $10 \% \mathrm{CO}_{2}$.

Cell viability assay. The MiaPaCa2cells were seeded in 384-well plates at a density of $1 \times 10^{3}$ cells/well in $100 \mu \mathrm{l}$ medium. A total of $24 \mathrm{~h}$ after seeding, the cells were treated with the indicated concentrations of statins $(0-100 \mu \mathrm{M})$ for $48 \mathrm{~h}$. Cell viability was determined by CellTiter-Glo ${ }^{\circledR}$ Luminescent Cell Viability Assay (Promega Corporation), according to the manufacturer's instructions. Briefly, at the end of incubation, the culture supernatant was replaced with CellTiter-Glo reagent $(1: 20 \mathrm{v} / \mathrm{v}$ dilution in fresh culture medium) (Promega Corporation). Plates were incubated at $37^{\circ} \mathrm{C}$ for $15 \mathrm{~min}$ and absorbance was measured at $490 \mathrm{~nm}$ using an Omega microplate reader (IMGEN Technologies).

Drug effect assay. The drug effect was determined by Cell Counting Kit-8 (CCK-8) assay. Briefly, 3,000 cells/well were seeded into a 96-well plate and incubated overnight in a cell culture incubator $\left(37^{\circ} \mathrm{C}, 95 \%\right.$ humidity). Cells were then treated with different concentrations ( 2 and $20 \mu \mathrm{M})$ of statins. Following incubation, the medium in each well was replaced with fresh culture medium containing $10 \mu \mathrm{l} \mathrm{CCK-8} \mathrm{(Dojindo}$ Molecular Technologies, Inc.). The plates were incubated for an additional $2 \mathrm{~h}$ in a cell culture incubator $\left(37^{\circ} \mathrm{C}, 95 \%\right.$ humidity), and absorbance was determined at $450 \mathrm{~nm}$ using a microplate spectrophotometer.

Reverse transcription-quantitative $(R T-q) P C R$. Total RNA was extracted from cells using TRIzol reagent (Invitrogen; Life Technologies; Thermo Fisher Scientific, Inc.) according to manufacturer's instructions. Reverse transcription was performed with RevertAid First Strand cDNA Synthesis kit (cat. no. K1622; Thermo Fisher Scientific, Inc.) according to the manufacturer's instructions. RT-qPCR was conducted using SYBR Green (ABgene) according to the manufacturer's instructions. The primer sequences used in $\mathrm{qPCR}$ were as follows: Forward, 5'-CGCTGGCGGTACTGAAGTC-3' and reverse, 5'-GAGGAACGGTGACATGCTCAT-3' for CCNA2; forward, 5'-CGCTACCCCTCAGAGGACAA-3' and reverse, 5'-ACAGACATCGGTG-3' for LZTS3; forward, 5'-CATGTA CGTTGCTATCCAGGC-3' and reverse, 5'-CTCCTTAAT GTCACGCACGAT-3' for $\beta$-actin (ACTB). The primers were obtained from Funengbio Co., Ltd. PCR amplification was performed using the following thermocycling conditions: $95^{\circ} \mathrm{C}$ for $30 \mathrm{sec}$, followed by 40 cycles at $95^{\circ} \mathrm{C}$ for $5 \mathrm{sec}, 60^{\circ} \mathrm{C}$ for $34 \mathrm{sec}$, and a melt curve stage. All experiments were 

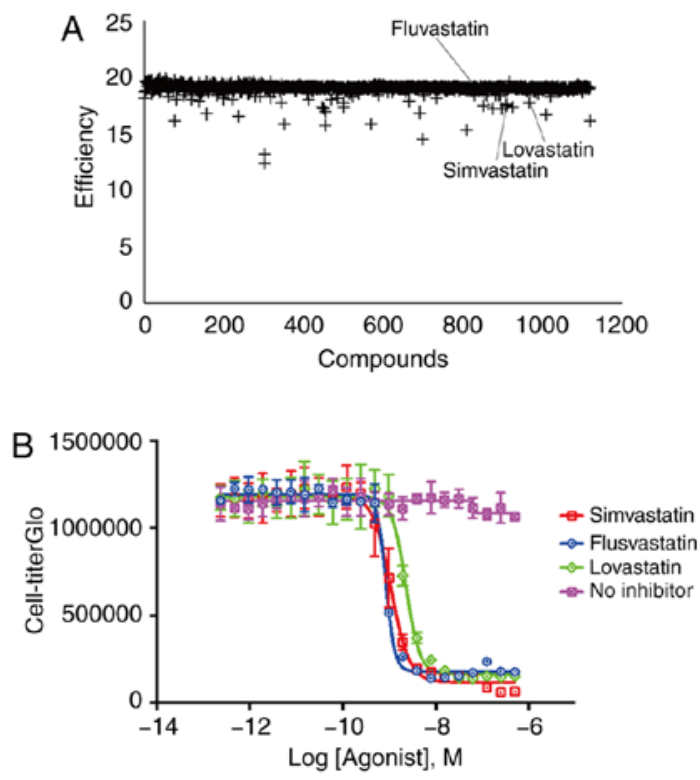

Figure 1. Statins are potential drugs for pancreatic cancer treatment. (A) Screening for potential drugs in MiaPaCa2 cells. A total of 1,280 compounds from the Prestwick Chemical library were screened. (B) Three statins were validated for the suppression of BIRC5-GLuc activity in MiaPaCa2. Various concentrations of Lovastatin, Simvastatin and Fluvastatin were used to analyze luciferase activity by CellTiter-Glo ${ }^{\circledR}$ Luminescent Cell Viability Assay.

performed in triplicate. The relative gene expression level was calculated using the $2^{-\Delta \Delta \mathrm{Cq}}$ method (12), and ACTB was used as the internal control.

Effects of statins on cancer cell colony formation. In each 6 -well plate, 400 cells were seeded and cultured for $24 \mathrm{~h}$. The culture medium was then changed to 5, 10, 15, 20 and $25 \mu \mathrm{M}$ statin-containing medium, and cells were incubated for 9 days, with DMSO as the control. The cells were washed with PBS and fixed with $100 \%$ methanol for $10 \mathrm{~min}$ at room temperature. Crystal violet (1\%) staining buffer (cat. no. C0121; Beyotime Institute of Biotechnology) was then added into the plates. Following incubation for $30 \mathrm{~min}$ at $37^{\circ} \mathrm{C}$, the crystal violet staining buffer was removed from the plates, which were then washed with de-ionized water. After the plates were dried at room temperature, the colonies in each plate were counted to measure the colony formation rate. The colonies were visualized with a general camera. Only colonies containing $\geq 50$ cells were counted as clonogenic survivors.

RNA-seq for statin-treated pancreatic cancer cells. PANC1 and $\mathrm{MiaPaCa} 2$ cells were collected following treatment or no treatment with 2 and $20 \mu \mathrm{M}$ of the three statins for $48 \mathrm{~h}$ (3 replicates per sample). Total RNAs were extracted using the RNeasy Mini kit (Qiagen AB), and the quality of the RNA was evaluated using Agilent Bioanalyzer 2100 (Agilent Technologies, Inc.). Sequence libraries were prepared using a TruSeq Stranded mRNA Library Prep kit for NeoPrep (Illumina, Inc.), according to the manufacturer's instructions, and sequenced using an Illumina HiSeq 2000 platform. FastQC (https://github.com/s-andrews/FastQC) was used for quality control of the sequenced data (13). RNA-seq data were trimmed using Trimmomatic (http://www.usadellab. org $/ \mathrm{cms} /$ ?page=trimmomatic) to remove and filter low-quality sequencing data and the adapters (14). The human genome NCBI GRCh38 (15) and its corresponding transcriptome gene annotation was used for read alignment. The TopHat alignment tool was used for alignment with default parameter settings (16).

Construction of weighted gene co-expression network analysis (WGCNA). WGCNA was used for scale-free network topology analysis of RNA-seq data (17). The WGCNA R package was used to cluster highly correlated genes and determine clusters in which gene expression was associated with the examined characteristics. An adjacency matrix based on expression correlation was created using a soft threshold procedure to allow scale-free topology. The clusters created by WGCNA were referred to as modules, and the minimum number of genes in a module was set to 30. The functional annotation tool Database for Annotation, Visualization and Integrated Discovery (DAVID) Bioinformatics Resources 6.8 was used to determine Gene Ontology terms enriched by the identified genes. DAVID analyses were performed using genes corresponding to significant WGCNA modules.

DAVID analysis. DAVID (http://david.abcc.ncifcrf.gov) Functional Annotation Bioinformatics Microarray Analysis was used to identify significantly enriched Gene Ontology (GO) and Kyoto Encyclopedia of Genes and Genomes (KEGG) terms among the genes that were differentially expressed in control samples $(18,19)$. Statistically overrepresented GO and KEGG categories with a $\mathrm{P} \leq 0.05$ were considered significant.

Survival and ROC analysis. To explore the potential prognostic value of the hub-gene, the Gene Expression Profiling Interactive Analysis (GEPIA) database was used to perform overall and disease-free survival analysis, and the log-rank tests were used to measure statistical significance (20).

Statistical analysis. All experiments in the present study were independently performed in triplicate. Data are presented as the mean \pm SEM. All graphs were plotted and analyzed with GraphPad Prism Software (GraphPad Prism version 7.1 for Windows; GraphPad Software, Inc.) and one-way ANOVA followed by Dunnett's multiple comparisons test. $\mathrm{P}<0.05$ was considered to indicate a statistically significant difference.

\section{Results}

Statins identified through medium throughput screening of pancreatic cancer cell lines from the Prestwick Chemical Library. The survivin gene, also known as BIRC5, plays a central role in cancer cell survival and proliferation, and has therefore become a promising therapeutic target for pancreatic cancer vaccines and therapeutics (21). In order to discover small molecular compounds that could suppress BIRC5 gene expression and pancreatic cancer cell proliferation, a high-content immunofluorescence screening assay utilizing an enhanced BIRC5 super-promoter system to drive the expression of dual Gaussia luciferase (GLuc) and sr39 thymidine kinase (sr39TK) reporter genes was developed (22). The screening incorporated 1,280 compounds from the Prestwick Chemical library. Of 
A
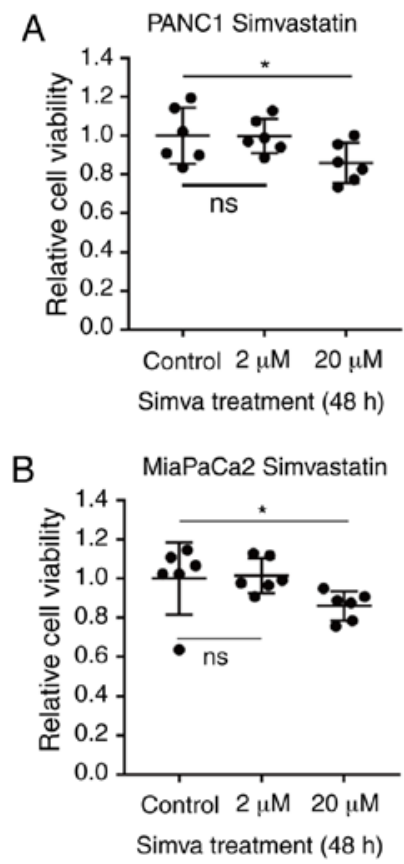
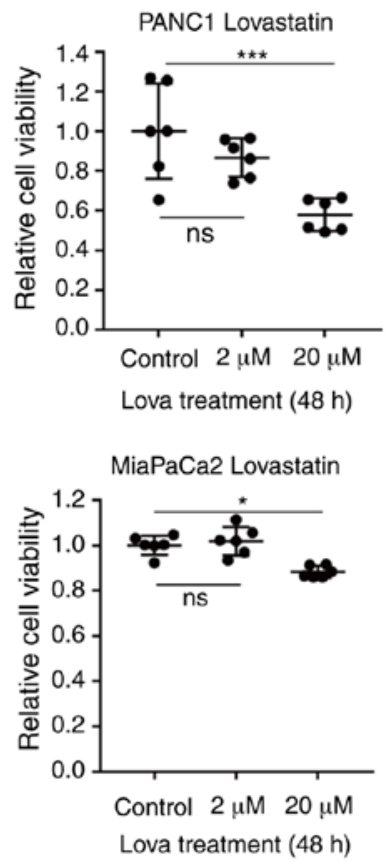
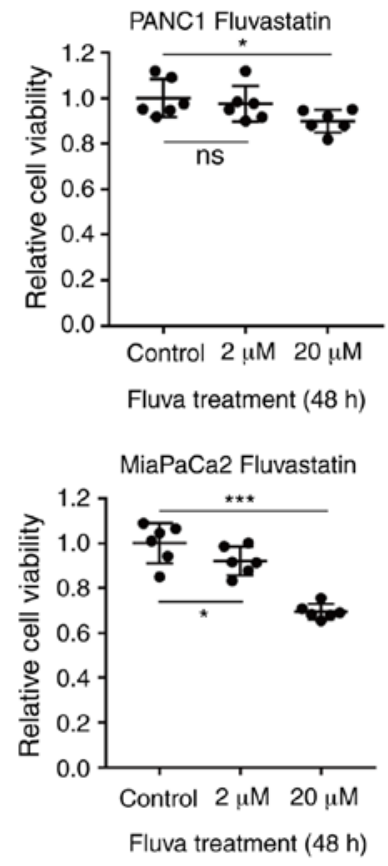

C

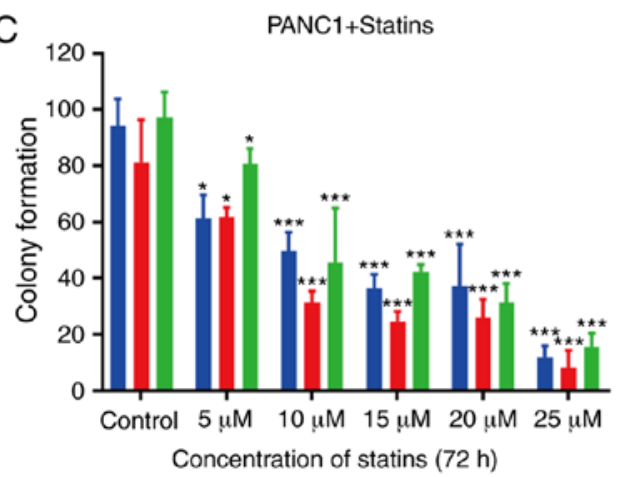

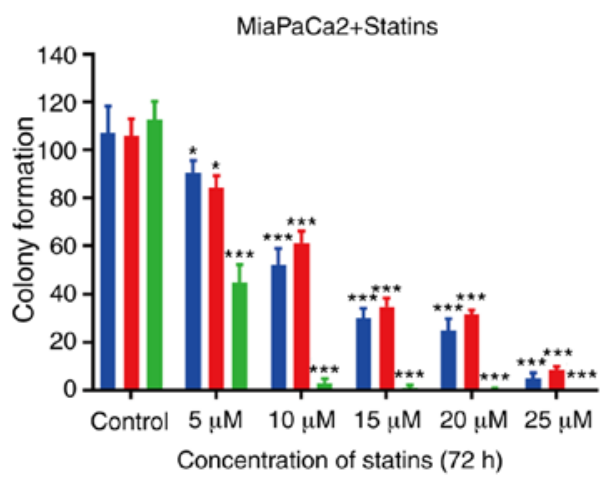

Figure 2. Statins suppress the proliferation of pancreatic cancer cells in a concentration-dependent manner. (A and B) CCK-8 assays revealed that high-concentration statins significantly inhibited the proliferation of (A) PANC1 and (B) MiaPaCa2 cells. The cancer cells were treated with statins for $24 \mathrm{~h}$ at the indicated concentrations $(2$ and $20 \mu \mathrm{M}){ }^{*} \mathrm{P}<0.05$ and ${ }^{* * * *} \mathrm{P}<0.01$ vs. the control. (C) The statins significantly inhibited colony formation in a concentration-dependent manner. The cancer cells were treated with various concentrations of statins (Control, 0, 5, 10, 15, 20 and $25 \mu \mathrm{M}$ ) for $72 \mathrm{~h}$. Three independently cultured replicates were performed per experimental condition. ${ }^{*} \mathrm{P}<0.05$ and ${ }^{* * * *} \mathrm{P}<0.01$ vs. the control. CCK-8, Cell Counting Kit-8.

all tested compounds, three statins (lovastatin, simvastatin and fluvastatin) were successfully identified to be consistently and potently effective at blocking BIRC5-induced Gaussia luciferase expression (Fig. 1A and B). These results indicated that all three statins identified through medium throughput screening could functionally suppress the cell proliferation of pancreatic cancer cells, which may have a potential clinical application value.

Statins significantly inhibit pancreatic cancer cell proliferation in a concentration-dependent manner. A previous study suggested that, although the MiaPaCa2 and PANC1 were commonly used pancreatic cancer cell lines, these two cell lines had a marked difference in response to various drugs (23). To further characterize the antitumor effects of the three statins on pancreatic cancer, the MiaPaCa2 and PANC1cell lines were used in the following assays. The MiaPaCa2 and PANC1 cells were incubated with fluvastatin, lovastatin and simvastatin at either a low $(2 \mu \mathrm{M})$ or a high $(20 \mu \mathrm{M})$ concentration. CCK-8 assays revealed that all three statins induced cell growth inhibition in both cell lines following high-concentration treatment, but not with low-concentration treatment (Fig. 2A and B). Among the three statins, lovastatin exhibited a relatively more efficient inhibition of PANC1 cell proliferation, while fluvastatin exhibited a more efficient suppression of $\mathrm{MiaPaCa} 2$ cell proliferation. In addition, a colony formation assay was carried out on the $\mathrm{MiaPaCa} 2$ and PANC1 cells treated with different concentrations of these three statins. The colony formation assay revealed that $5 \mu \mathrm{M}$ statins slightly suppressed the proliferation of PANC1 cells $(\mathrm{P}<0.05$ and $\mathrm{P}<0.01)$. This result is inconsistent with Fig. 2B, which is likely due to different concentrations of statins $(5 \mu \mathrm{M}$ vs. $2 \mu \mathrm{M})$ that we used. Consistent with the CCK-8 assay, the results revealed that only at a high concentration $(\geq 5 \mu \mathrm{M})$ could the three statins significantly attenuate the proliferation of both pancreatic cancer cell lines (Figs. 2C and S1). Notably, lovastatin and fluvastatin had diverse inhibitory effects on $\mathrm{MiaPaCa} 2$ and PANC1 cells, respectively. In conclusion, these results revealed that the high-concentration statins significantly inhibited the proliferation of both pancreatic cancer cell lines, but the inhibitory efficiencies of various statins on these two pancreatic cancer cell lines were diverse. 
A

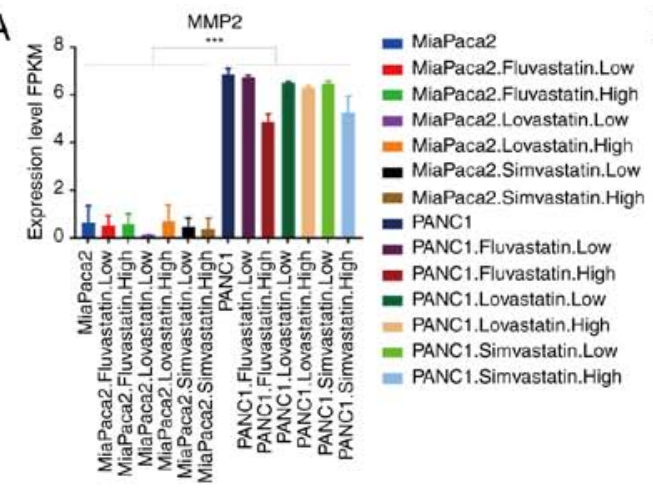

B

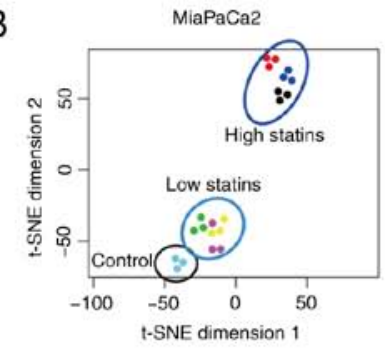

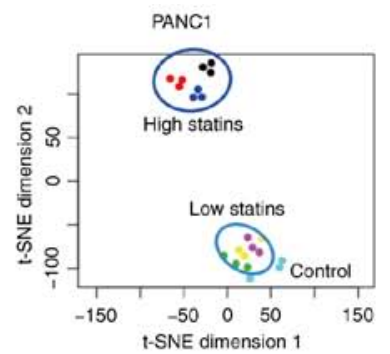
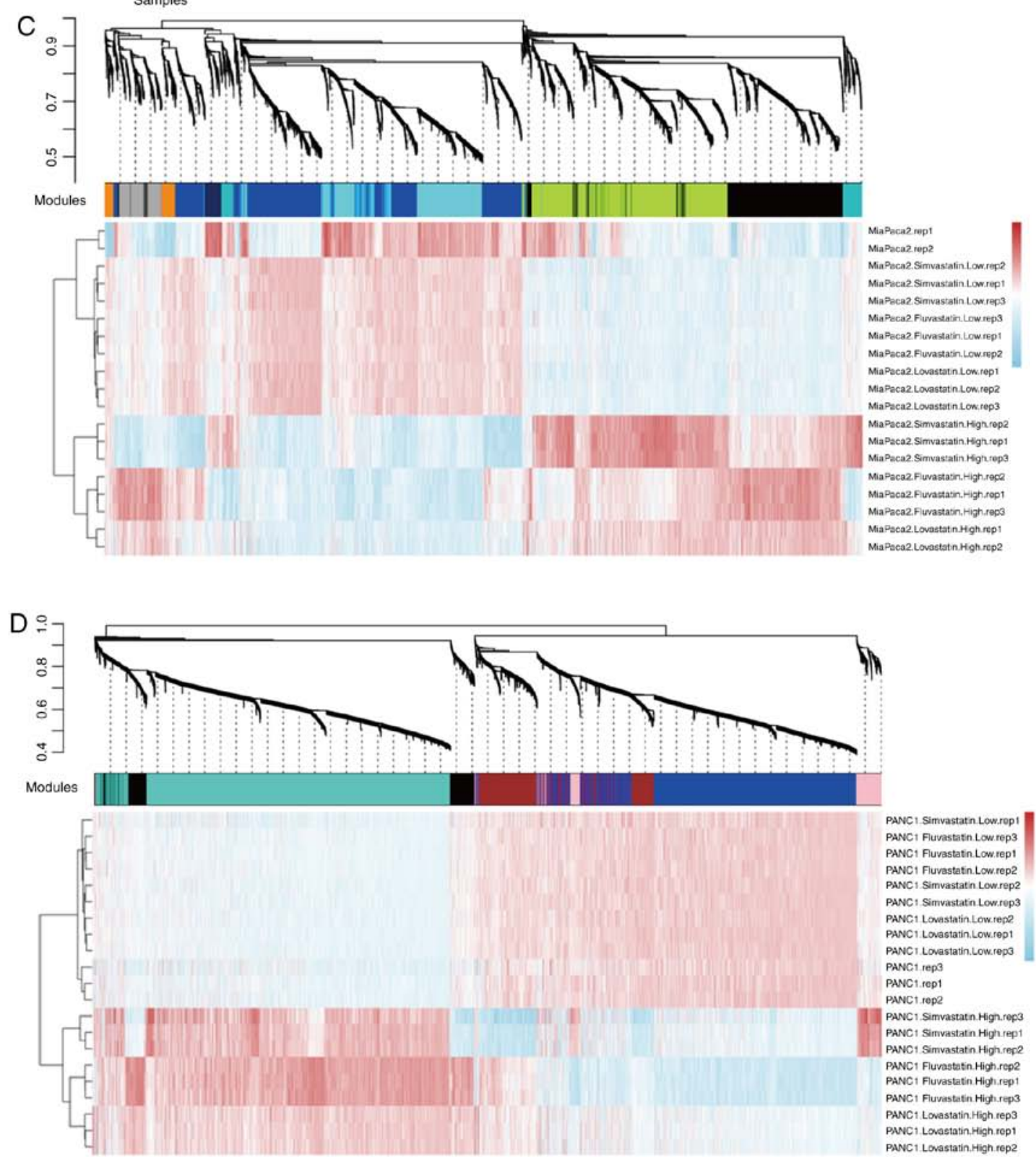

Figure 3. RNA-seq analysis of MiaPaCa2 and PANC1 cells treated with low- and high-concentration statins. (A) MMP2 expression levels in RNA-seq data of MiaPaCa2 and PANC1 cells. ${ }^{* * *} \mathrm{P}<0.01$. (B) Clustering of the statin-treated pancreatic cancer cells with t-SNE. (C and D) WGCNA revealed gene-network modules in the statin-treated pancreatic (C) MiaPaCa2 and (D) PANC1 cancer cells. WGCNA, weighted gene co-expression network.

Identification of statin-induced transcriptome alterations in pancreatic cancer cells through RNA-seq. In order to investigate the transcriptional alterations in pancreatic cancer cell lines under various treatment conditions with the three statins,
RNA-seq was performed on MiaPaCa2 and PANC1 cells treated with either a low- or high-concentration of the three statins. The two cancer cell lines were treated with low- $(2 \mu \mathrm{M}$ group) and high (20 $\mu \mathrm{M}$ group)-concentration statins for 
A

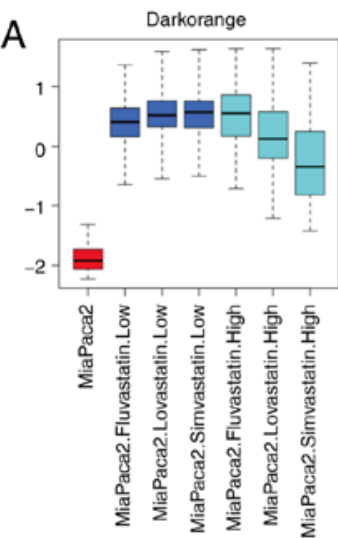

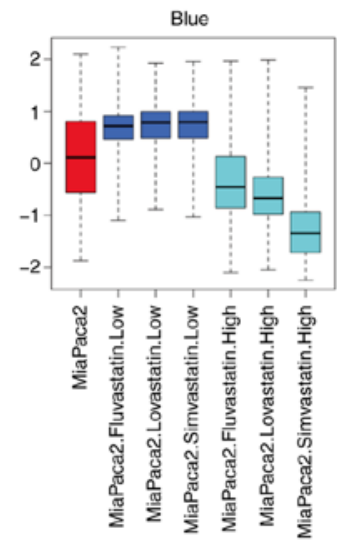

B
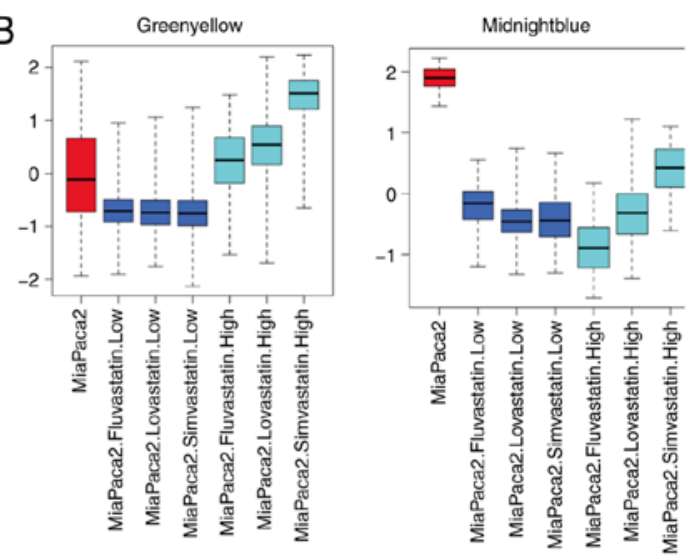

C

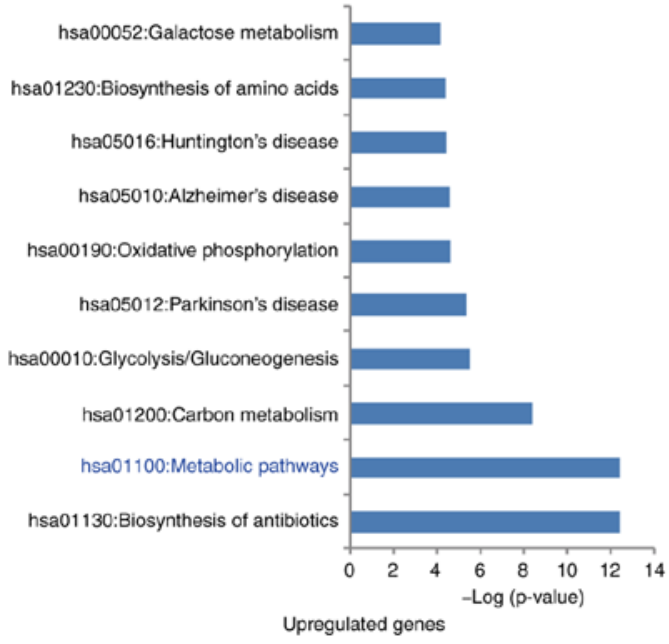

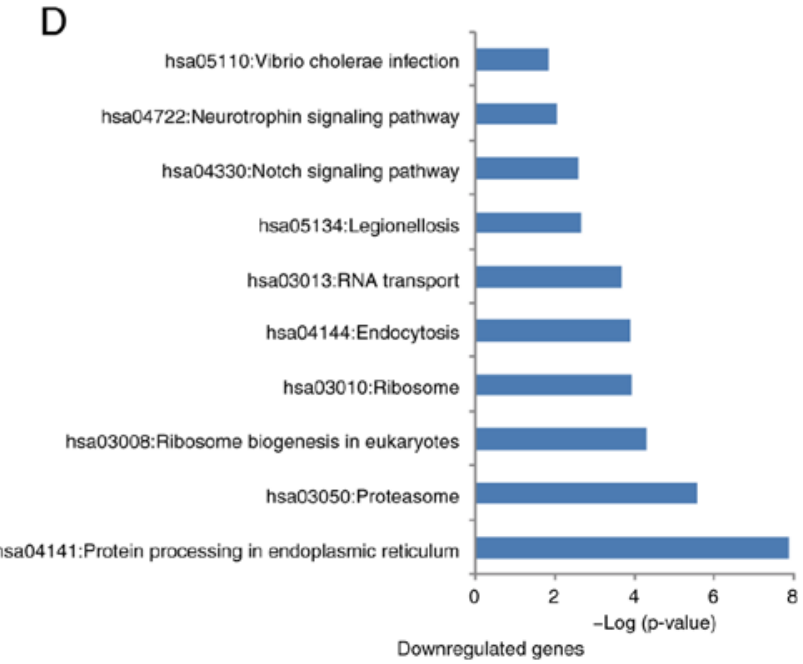

Figure 4. Effect of low-concentration statins on MiaPaCa2 cells. (A and B) Low-concentration statin treatment of MiaPaCa2 cells specifically enriched differentially expressed genes, including (A) upregulated and (B) downregulated genes. WGCNA revealed that genes in the dark-orange and blue modules were significantly upregulated, while genes in the green-yellow and midnight-blue modules were significantly downregulated. (C and D) DAVID-KEGG analysis of these differentially expressed genes. Top 10 enriched signaling pathways of $(C)$ upregulated and (D) downregulated genes (P<0.01). WGCNA, weighted gene co-expression network analysis; DAVID, Database for Annotation, Visualization and Integrated Discovery; KEGG, Kyoto Encyclopedia of Genes and Genomes.

$48 \mathrm{~h}$ before the cells were harvested for RNA-seq library preparation. The signature gene expression of $\mathrm{MiaPaCa} 2$ and PANC1 cells was validated by examining the endogenous MMP2 expression of RNA-Seq data between these two cell lines (Fig. 3A) (24). The transcriptional profiles of all three statin-treated cancer cells were distinguished from those of the original cancer cells. 2D t-SNE of whole genome gene expression profiles in these treated cells revealed that the low-and high-concentration treatment groups clustered separately (Fig. 3B). The high-concentration statins markedly changed the expression of genes in both cell lines. On the contrary, the low-concentration statins had relatively minor effects. Only a subset of genes was upregulated in low-concentration statin-treated $\mathrm{MiaPaCa} 2$ cells, which was not observed in PANC1 cells (Fig. S2). To further assess the transcriptome dynamics of statin-induced gene alterations, the WGCNA was used, and multiple gene-network modules associated with high- and low-concentration statins, as well as three individual statins, were obtained (Table SI). In MiaPaCa2 cells, 8 modules that were possibly associated with the treatment of various statins were identified (Figs. 3C and S3A), while 5 modules were identified in PANC1 cells (Figs. 3D and S3B). As compared to those untreated cancer cells, high-concentration treatment groups exhibited more robust gene expression alterations than that in the low-concentration treatment groups. A high number of upregulated and downregulated genes were identified in the high-concentration groups, which may contribute to the cell proliferation inhibition effects of the statins.

Low-concentration statins stimulate considerable gene expression changes in MiaPaCa2, but not in PANCl cells. As revealed by a previous study, the difference in the response to various drugs between MiaPaCa2 and PANC1 was marked (23). A significant difference (3,028 different expression genes) was observed between the MiaPaCa2 and PANC1 cell lines in our RNA-seq data (Fig. S4A and B). KEGG analysis of these different expression genes revealed that the MiaPaCa2 cells exhibited a high level of metabolism-related gene expression (Fig. S4C), while the PANC1 cells exhibited a high level of cancer-related gene expression (Fig. S4D). The different transcriptome profiles of $\mathrm{MiaPaCa} 2$ and PANC1 suggest that they may have different effects on statin treatment. In response to treatment with low-concentration statins, the MiaPaCa2 cells behaved in a considerably more sensitive 

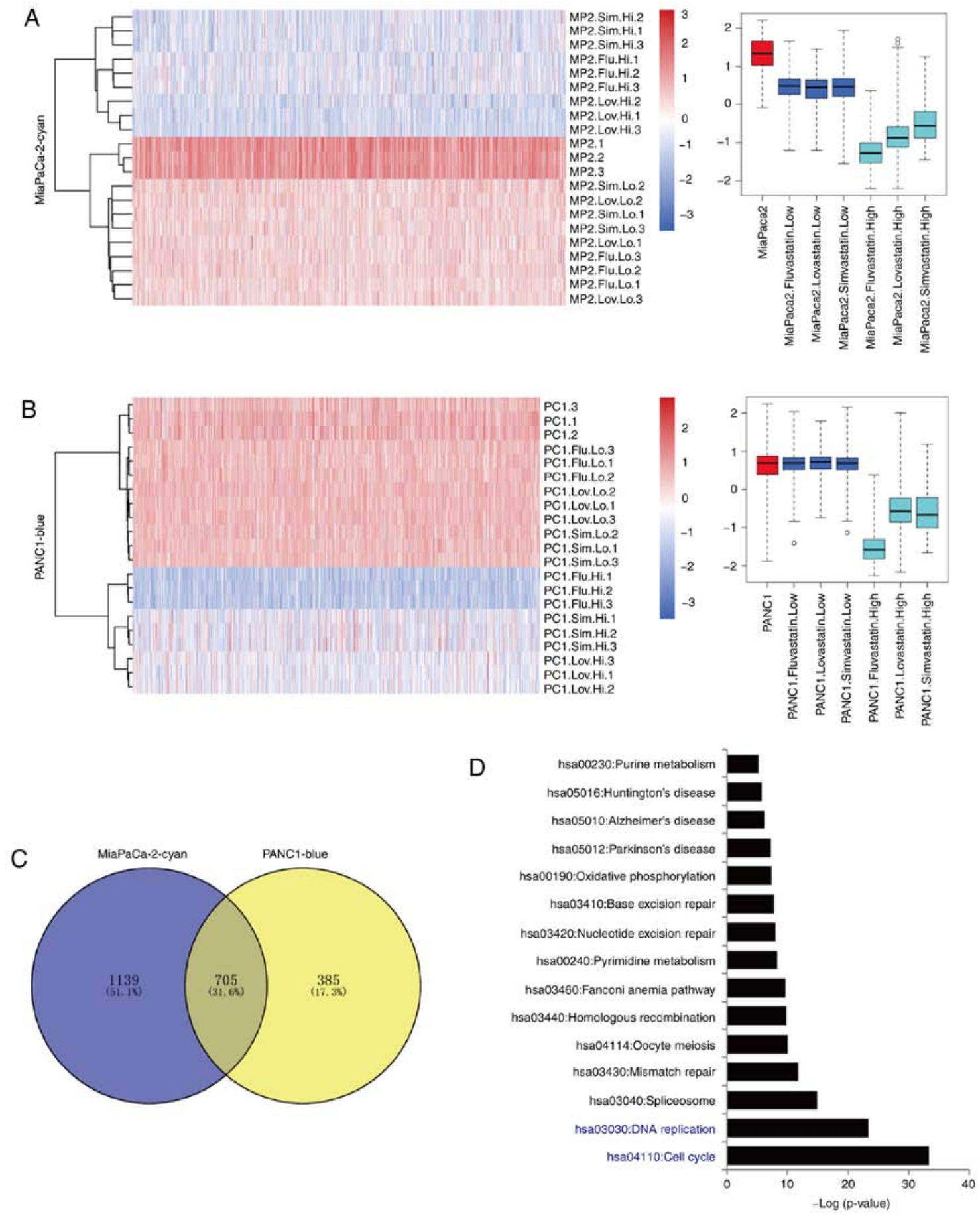

Figure 5. High-concentration statins significantly inhibit gene expression in the cell cycle and DNA replication signaling pathways. (A) Genes in the cyan module of $\mathrm{MiaPaCa} 2$ cells were significantly downregulated by high-concentration statins. (B) Genes in the blue module of PANC1 cells were significantly downregulated by high-concentration statins. (C) Common genes in the cyan module of MiaPaCa2 cells and blue modules of PANC1. (D) DAVID-KEGG analysis of these common inhibited genes. The enriched signaling pathways are presented $(\mathrm{P}<0.01)$. DAVID, Database for Annotation, Visualization and Integrated Discovery; KEGG, Kyoto Encyclopedia of Genes and Genomes.

way than the PANC1 cells. Similarly, the expression of a number of genes was significantly altered in statin-treated MiaPaCa2 cells, but not in PANC1 cells (Fig. S2). Additional WGCNA analysis also indicated that the PANC1 cells treated with a low-concentration statin exhibited a similar gene expression to that of original PANC1 cells. However, 4 modules were significantly changed in MiaPaCa 2 cells. In $\mathrm{MiaPaCa} 2$ cells treated with low-concentration statins, genes in the dark-orange [208 genes, module eigengene
(KME) dark-orange $>0.5$ ] and blue $(1,631$ genes, KME blue $>0.5$ ) modules were significantly upregulated, while genes in midnight-blue (158 genes, KME midnight-blue $>0.5$ ) and green-yellow $(1,575$ genes, KME green-yellow $>0.5)$ modules were significantly downregulated $(\mathrm{KME}$ value=eigengene connectivity) (Fig. 4A and B). Further DAVID GO and KEGG analysis revealed that, upregulated genes enriched in the signaling pathways of the biosynthesis of antibiotics $(\mathrm{P}<0.001)$, metabolism $(\mathrm{P}<0.001)$, carbon metabolism 

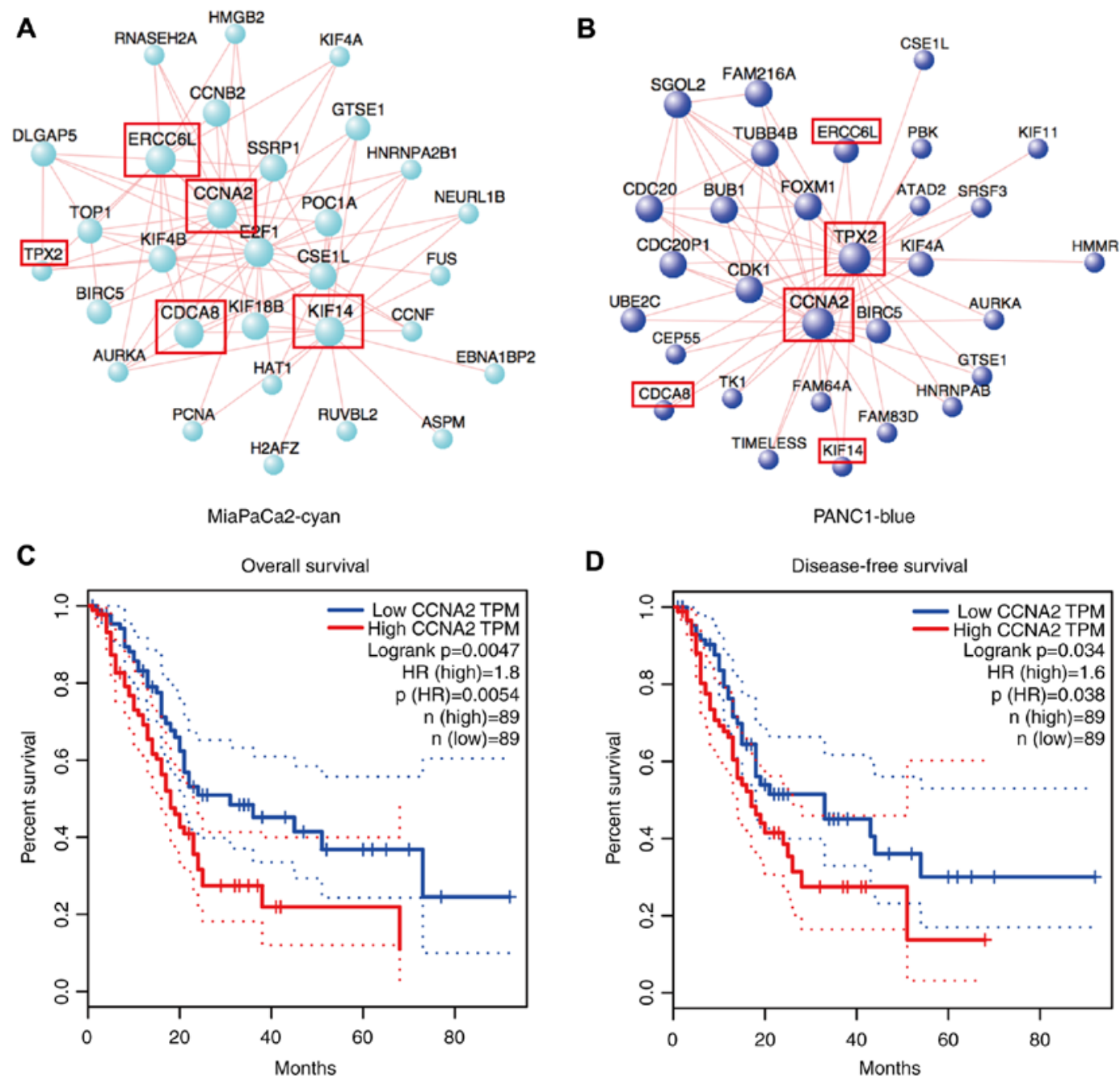

Figure 6. Hub gene analysis reveals that CCNA2 is the core inhibited gene of statins in pancreatic cancer cells. (A) Hub gene analysis of the cyan module of MiaPaCa2 cells. (B) Hub gene analysis of the blue module of PANC1 cells. The red box shows the common genes in the cyan module of MiaPaCa2 and the blue module of PANC1 cells. The size of the ball represents the weight of the gene in the module. (C and D) The reduced expression level of CCNA2 indicated poor prognosis in pancreatic cancer in the GEPIA database, including poor (C) overall and (D) disease-free survival. Red, pancreatic cancer patients with a high CCNA2 expression; blue, pancreatic cancer patients with a low CCNA2 expression. P $<0.05$. CCNA2, cyclin A2; GEPIA, Gene Expression Profiling Interactive Analysis.

$(\mathrm{P}<0.001)$ and glycolysis/gluconeogenesis $(\mathrm{P}<0.001)$, while downregulated genes were significantly enriched in the signaling pathways of the protein processing in endoplasmic reticulum $(\mathrm{P}<0.001)$, proteasome $(\mathrm{P}<0.001)$, ribosome biogenesis in eukaryotes $(\mathrm{P}<0.001)$ and ribosome $(\mathrm{P}<0.001)$ (Fig. 4C and D, Table SII). In conclusion, these results indicated that low-concentration statins did not influence the PANC1 cells, but they affected gene expression in MiaPaCa2 cancer cells by upregulating the metabolism-related genes and downregulating the ribosome-related genes.

High-concentration statins significantly suppress the proliferation of pancreatic cancer cells by inhibiting the cyclin A2 (CCNA2)-based cell cycle pathway. In PANC1 cells treated with high-concentration statins, the most significant variations were the gene upregulation in the turquoise module $(2,327$ genes, KME turquoise $>0.5)$ and downregulation in the blue module (1,844 genes, KME blue $>0.5$; Table SI). In $\mathrm{MiaPaCa} 2$ cells, treatment with high-concentration statins caused gene upregulation in the black (1,231 genes, KME black
$>0.5)$ and green-yellow (1,575 genes, KME green-yellow $>0.5)$ modules, and gene downregulation in the cyan $(1,090$ genes, KME cyan $>0.5)$ and blue $(1,631$ genes, KME blue $>0.5)$ modules (Table SI). Combined with the significant inhibition of MiaPaCa2 cells by fluvastatin (Fig. 2B and C), the downregulated genes in the cyan module and upregulated genes in the black module may play a vital role on the inhibition of pancreatic cancer $\mathrm{MiaPaCa} 2$ cell proliferation by statins.

In order to identify the common effects of statins on pancreatic cancer cells, an integrated analysis of these two cell lines was conducted. The cyan module of the MiaPaCa2 cell line and blue module of the PANC1 cell line displayed a concentration-dependent expression inhibition induced by all three statins (Fig. 5A and B). The detailed inhibition of the expression of these genes is presented. The gene lists from these 2 modules were compared, and 705 overlapping genes that were inhibited by statins were identified (Fig. 5C). KEGG analysis of these genes revealed significant enrichment in the signaling pathways of cell cycle $(\mathrm{P}<0.001)$, DNA replication $(\mathrm{P}<0.001)$ and spliceosome $(\mathrm{P}<0.001)$ (Fig. 5D). Further 

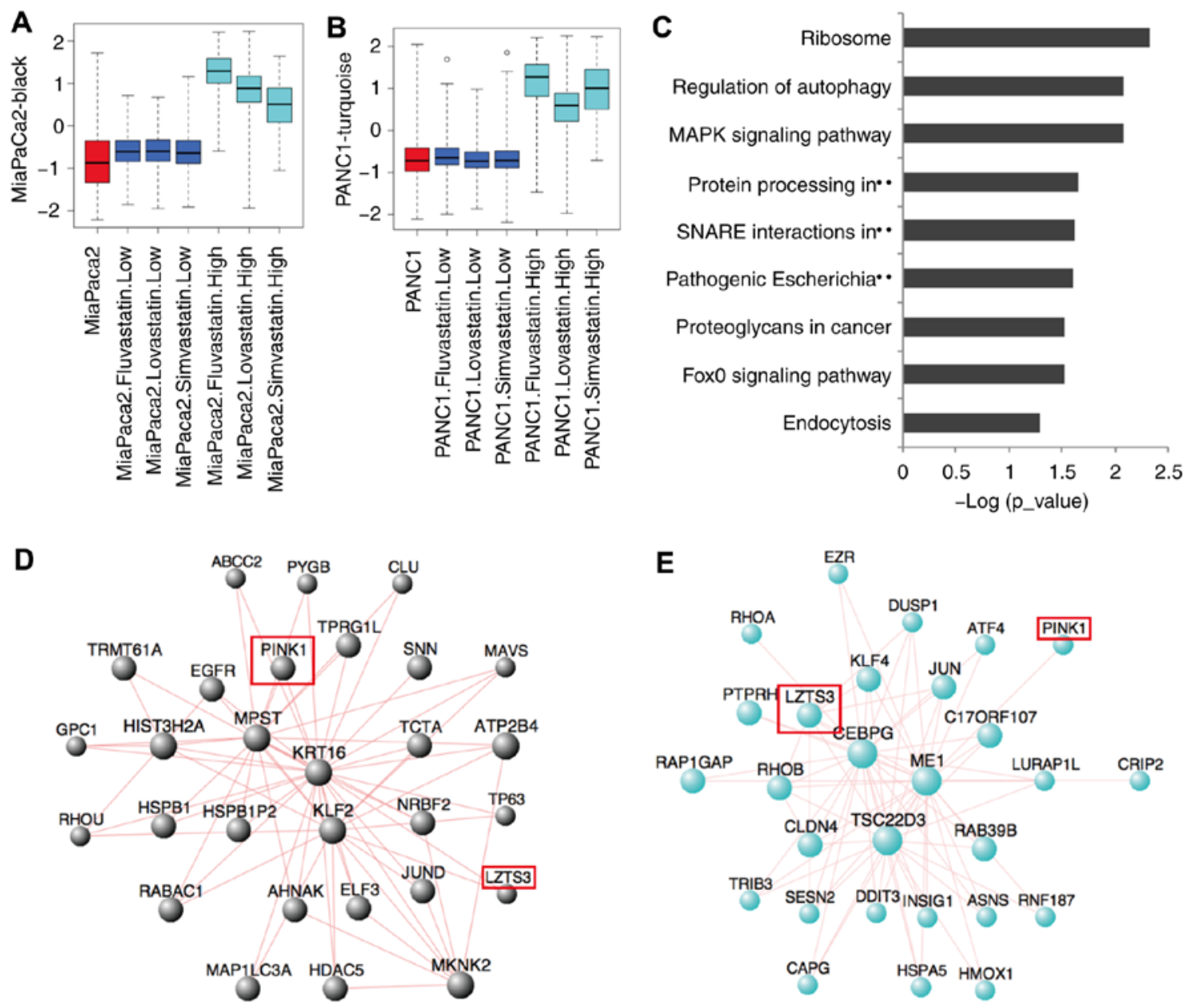

Figure 7. High concentration statins significantly upregulated the genes in the signaling pathways of ribosome and autophagy. (A) Genes in the black module of $\mathrm{MiaPaCa} 2$ cells were significantly upregulated by high-concentration statins. (B) Genes in the turquoise module of PANC1 cells were significantly upregulated by high-concentration statins. (C) DAVID-KEGG analysis of these common upregulated genes. The enriched signaling pathways are presented $(\mathrm{P}<0.05)$. (D) Hub gene analysis of the black module of MiaPaCa2 cells. (E) Hub gene analysis of the turquoise module of PANC1 cells. The red box shows the common genes in the black module of MiaPaCa2 cells and turquoise module of PANC1 cells. The size of the ball represents the weight of the gene in the module. DAVID, Database for Annotation, Visualization and Integrated Discovery; KEGG, Kyoto Encyclopedia of Genes and Genomes.

hub-gene analysis of these 2 modules was performed. The result revealed that they shared some common genes that were also involved in the cell cycle pathway, such as CCNA2, ERCC6L, $T P X 2, K I F 14$ and $C D C A 8$. In these two modules, CCNA2 was the common main affecting gene (Fig. 6A and B), while in pancreatic cancer, the high expression level of $C C N A 2$ was significantly associated with poor prognosis, including overall $(\mathrm{P}=0.0047)$ and disease-free survival $(\mathrm{P}=0.034$; Fig. $6 \mathrm{C}$ and $\mathrm{D})$. The suppressed CCNA2 by high-concentration statins were also validated with RT-qPCR (Fig. S5A-C). These data demonstrated the inhibition of a common conserved gene by statins in pancreatic cancer cells, and indicated that statins potentially inhibited cancer cell proliferation through the suppression of the cell cycle pathway, based on the core gene CCNA2.

High-concentration statins significantly upregulate the genes involved in ribosome and autophagy pathways. These statins could also induce high gene expression in pancreatic cancer cells. In the black module (1,297 genes; Figs. 7A and S6A) of the $\mathrm{MiaPaCa} 2$ cell line and turquoise module (2,519 genes; Figs. 7B and S6B) of the PANC1 cell line, a markedly high gene expression of 635 genes was induced by high-concentration treatment with all three statins (Fig. S6C). KEGG analysis of these genes revealed significant enrichment in the ribosome $(\mathrm{P}<0.001)$, regulation of autophagy $(\mathrm{P}<0.001)$ and MAPK signaling $(\mathrm{P}<0.001$; Fig. $7 \mathrm{C})$ pathways. Further hub-gene analysis of these 2 modules revealed that the MiaPaCa2 and PANC1 cell lines have different core genes for statin-induced pathway activation. In the black module of the MiaPaCa2 cell line, the PTEN induced kinase 1 (PINK1), MPST, KRT16, KLF2 and HIST3H2A genes form the core gene group (Fig. 7D), while in the turquoise module of the PANC1 cell line, the leucine zipper tumor suppressor family member 3 (LZTS3), CEBPG, $M E 1$ and TSC22D3 genes form the core gene group (Fig. 7E). Both PINK1 and LZTS3 appeared in the hub genes of these two modules, but they have different contributions. The induced expression of LZTS3 by high-concentration statins were validated with RT-qPCR (Fig. S5D-F). These results indicated that high-concentration statins could induce massive gene expression changes in both pancreatic cancer cells, and although the hub genes of different pancreatic cancer cells were slightly different, their enriched signaling pathways were identical. Both were involved in the ribosome, autophagy and MAPK signaling pathways. 
In addition to the aforementioned common effects, these high-concentration statins could also induce the expression of different genes in the MiaPaCa2 and PANC1 cell lines (Fig. 3C and D). In MiaPaCa2 cells, genes from the dark-grey module were significantly upregulated in fluvastatin-treated cells. KEGG analysis of these genes revealed a significant enrichment in the pathways of oxidative phosphorylation and ribosome $(\mathrm{P}<0.001$; Table $\mathrm{SIII})$. Genes in the dark-turquoise module were significantly upregulated in simvastatin-treated cells. KEGG analysis of these genes revealed significant enrichment in the pathways of the $\mathrm{NF}-\kappa \mathrm{B}$ signaling pathway $(\mathrm{P}=0.007$; Table SIII). In PANC1 cells, genes in the pink module were significantly upregulated in simvastatin-treated cells. KEGG analysis of these genes revealed that the signaling pathways of the oxidative phosphorylation and ribosome were significantly enriched $(\mathrm{P}<0.001)$, which was consistent with the dark-grey module in MiaPaCa2 cells (Table SIII). However, fluvastatin-treated PANC1 cells specifically upregulated the genes in the black module, which was enriched in the signaling pathways of the protein processing in endoplasmic reticulum and endocytosis $(\mathrm{P}<0.001)$. These results indicated that, in addition to common transcriptional influences, these three statins exhibited different effects on the signaling pathways of the MiaPaCa2 and PANC1 cell lines.

\section{Discussion}

Recent studies have shown that statins can be used for cancer prevention or therapeutics (25-27), due to their pleiotropic effects through multiple biological pathways, particularly the mevalonate pathway (28). Among prenylated proteins, the activated RAS proteins via farnesylation, constitute central regulators of numerous cellular functions. It has been shown that $>90 \%$ of pancreatic cancer harbor activation mutations of the KRAS oncogene (29). Therefore, the beneficial effects of statins on pancreatic cancer treatment are biologically plausible, although findings from epidemiological studies on their therapeutic benefits are inconsistent to some extent (30-37).

Previous studies have revealed that in addition to the known functions on cholesterol metabolism (38), the statins have some other pleiotropic effects, involvingthe regulation of the NF- $\mathrm{KB}$ signaling pathway (39), NOTCH signaling pathway $(40,41)$ and endocytosis $(42,43)$. The present study indicated that different statins may have their unique function on cancer cells. For example, high-concentration fluvastatin inhibited gene expression associated with the NF- $\kappa \mathrm{B}$ signaling pathway, whereas high-concentration simvastatin upregulated the expression of $\mathrm{NF}-\kappa \mathrm{B}$ signaling genes (dark turquoise module of MiaPaCa2). Genes related to the NOTCH signaling pathway were suppressed by low-concentration statins. By contrast, the high-concentration simvastatin significantly upregulated NOTCH signaling genes (green-yellow module of $\mathrm{MiaPaCa} 2$ ). For endocytosis, low-concentration statins significantly inhibited genes related to endocytosis in both $\mathrm{MiaPaCa} 2$ and PANC1. The inhibition of endocytosis genes was also observed in high-concentration simvastatin-treated PANC1 cells, but not in high-concentration Fluvastatin-treated PANC1 cells (black module of PANC1). Collectively, our transcriptome analyses revealed that although these three statins exert similar function on pancreatic cancer, the concentration of statins and different products of statins may have different outcomes.

It is well known that the amount of drugs that could reach cancer cells in the human body is limited (44), and therefore studying drug response at low concentrations is important. The present study indicated that the concentration of statins significantly affects its potential cell death-inducing function. The low-concentration statins $(\leq 2 \mu \mathrm{M})$ did not influence the gene expression associated with the proliferation of pancreatic cancer cells. They could trigger transcriptomic changes in MiaPaCa 2 cells, but not in PANC1 cells. Notably, as compared with PANC1 cells, the MiaPaCa2 cells exhibited a high level of metabolism-related gene expression. In addition, low-concentration statins could significantly inhibit gene expression in ribosome and proteasome signaling pathways while upregulating gene expression in metabolism signaling pathways. These results suggested that statins may only exert limited antitumor effects in the treatment of metabolism-related pancreatic cancer. In addition, the low concentration of statins $(2 \mu \mathrm{M})$ used in the present study was markedly higher than the orally administered therapeutic doses (1-25 nM) (45). High-concentration statins $(20 \mu \mathrm{M})$ can induce pancreatic cancer cell death in vitro, and this concentration may potentially be achieved by targeted implantation. We should therefore be cautious when statins are used clinically to treat cancer in future, particularly when it comes to the statin concentrations and the metabolic status of the cancer cells $(46,47)$.

Although low-concentration statins did not function satisfactorily on pancreatic cancer cells, it was found that high-concentration statins could significantly inhibit the proliferation of cancer cells. High-concentration statins could significantly suppress gene expression in the cell cycle and DNA replication signaling pathways. However, they could also induce gene expression in the ribosome, autophagy and MAPK signaling pathways, which may eventually lead to therapeutic resistance (48-50). In conclusion, these results indicated that, although high-concentration statins can suppress pancreatic cancer satisfactorily, it is still necessary to consider combination therapy with other drugs, such as autophagy or MAPK inhibitors, to reduce potential resistance.

\section{Acknowledgments}

The excellent technical assistance of Dr Limei Cao and Dr Yongjin Zhang (The NHC Key Laboratory of Drug Addiction Medicine, The First Affiliated Hospital of Kunming Medical University, Kunming, China) is gratefully acknowledged.

\section{Funding}

The present study was supported by grants from the China Postdoctoral Science Foundation (grant no. 2020M673596XB), the National Natural Science Foundation of China (grant nos. 81903046, 3171101074, 81860100, 31860306, and 81870458), the Science and Technology Department of Yunnan Province (grant nos. 2018DH006 and 2018NS0086), the Yunling Scholar 
(grant no. YLXL20170002) and Yunnan Outstanding Youth Grant. The funders had no role in the study design, data collection, and analysis, decision to publish, or preparation of the manuscript.

\section{Availability of data and materials}

The datasets analyzed in the present study are available from the GEO repository, GEO GSE149566 (https://www.ncbi.nlm. nih.gov/geo/query/acc.cgi?acc=GSE149566).

\section{Authors' contributions}

KW, JY and HW conceived the study. CC, HW and JY performed all experiments. DK, YX, ZZ, FC, LZ, ZL, JS, HL and SHL prepared the reagents and samples. JY, HW and FCB analyzed the data. HW, JY, and CC wrote the manuscript, and $\mathrm{KW}$ and FCB reviewed the results and participated in the discussion about the manuscript. All authors read and approved the final manuscript.

\section{Ethics approval and consent to participate}

Not applicable.

\section{Patient consent for publication}

Not applicable.

\section{Competing interests}

The authors declare that they have no competing interests.

\section{References}

1. Rahib L, Smith BD, Aizenberg R, Rosenzweig AB, Fleshman JM and Matrisian LM: Projecting cancer incidence and deaths to 2030: The unexpected burden of thyroid, liver, and pancreas cancers in the United States. Cancer Res 74: 2913-2921, 2014.

2. Hamada T, Khalaf N, Yuan C, Babic A, Morales-Oyarvide V, Qian ZR, Nowak JA, Ng K, Kraft P, Rubinson DA, et al: Statin use and pancreatic cancer risk in two prospective cohort studies. J Gastroenterol 53: 959-966, 2018.

3. Oprea TI and Mestres J: Drug repurposing: Far beyond new targets for old drugs. AAPS J 14: 759-763, 2012.

4. Zhang Y, Liang M, Sun C, Qu G, Shi T, Min M, Wu Y and Sun Y: Statin use and risk of pancreatic cancer: An updated meta-analysis of 26 studies. Pancreas 48: 142-150, 2019.

5. Mitchell JD, Fergestrom N, Gage BF, Paisley R, Moon P, Novak E, Cheezum M, Shaw LJ and Villines TC: Impact of statins on cardiovascular outcomes following coronary artery calcium scoring. J Am Coll Cardiol 72: 3233-3242, 2018.

6. Mohammadkhani N, Gharbi S, Rajani HF, Farzaneh A, Mahjoob G, Hoseinsalari A and Korsching E: Statins: Complex outcomes but increasingly helpful treatment options for patients. Eur J Pharmacol 863: 172704, 2019.

7. Tamburrino D, Crippa S, Partelli S, Archibugi L, Arcidiacono PG, Falconi $\mathrm{M}$ and Capurso G: Statin use improves survival in patients with pancreatic ductal adenocarcinoma: A meta-analysis. Dig Liver Dis 52: 392-399, 2020.

8. Huang SW, Chyuan IT, Shiue C, Yu MC, Hsu YF and Hsu MJ: Lovastatin-mediated MCF-7 cancer cell death involves LKB1-AMPK-p38MAPK-p53-survivin signalling cascade. J Cell Mol Med 24: 1822-1836, 2020.

9. Xian G, Zhao J, Qin C, Zhang Z, Lin Y and Su Z: Simvastatin attenuates macrophage-mediated gemcitabine resistance of pancreatic ductal adenocarcinoma by regulating the TGF- $\beta 1 /$ Gfi- 1 axis. Cancer Lett 385: 65-74, 2017.
10. Kanvatirth P, Jeeves RE, Bacon J, Besra GS and Alderwick LJ: Utilisation of the Prestwick chemical library to identify drugs that inhibit the growth of mycobacteria. PLoS One 14: e0213713, 2019.

11. Moreau D, Vacca F, Vossio S, Scott C, Colaco A, Paz Montoya J, Ferguson C, Damme M, Moniatte M, Parton RG, et al: Drug-induced increase in lysobisphosphatidic acid reduces the cholesterol overload in Niemann-Pick type $\mathrm{C}$ cells and mice. EMBO Rep 20: e47055, 2019.

12. Livak KJ and Schmittgen TD: Analysis of relative gene expression data using real-time quantitative PCR and the 2(-Delta Delta C(T)) method. Methods 25: 402-408, 2001.

13. Brown J, Pirrung $M$ and McCue LA: FQC Dashboard: Integrates FastQC results into a web-based, interactive, and extensible FASTQ quality control tool. Bioinformatics 33: 3137-3139, 2017.

14. Bolger AM, Lohse $M$ and Usadel B: Trimmomatic: A flexible trimmer for Illumina sequence data. Bioinformatics 30: 2114-2120, 2014

15. Phan L, Hsu J, Tri LQ, Willi M, Mansour T, Kai Y, Garner J, Lopez J and Busby B: dbVar structural variant cluster set for data analysis and variant comparison. F1000Res 5: 673, 2016.

16. Trapnell C, Pachter L and Salzberg SL: TopHat: Discovering splice junctions with RNA-Seq. Bioinformatics 25: 1105-1111, 2009.

17. Wu H, Yu J, Li Y, Hou Q, Zhou R, Zhang N, Jing Z, Jiang M, $\mathrm{Li} Z$, Hua Y, et al: Single-cell RNA sequencing reveals diverse intratumoral heterogeneities and gene signatures of two types of esophageal cancers. Cancer Lett 438: 133-143, 2018.

18. Huang da W, Sherman BT and Lempicki RA: Systematic and integrative analysis of large gene lists using DAVID bioinformatics resources. Nat Protoc 4: 44-57, 2009.

19. Huang da W, Sherman BT and Lempicki RA: Bioinformatics enrichment tools: Paths toward the comprehensive functional analysis of large gene lists. Nucleic Acids Res 37: 1-13, 2009.

20. Tang Z, Li C, Kang B, Gao G, Li C and Zhang Z: GEPIA: A web server for cancer and normal gene expression profiling and interactive analyses. Nucleic Acids Res 45 (W1): W98-W102, 2017.

21. Wheatley SP and Altieri DC: Survivin at a glance. J Cell Sci 132: jcs223826, 2019.

22. Liu SH, Hong Y, Markowiak S, Sanchez R, Creeden J, Nemunaitis J, Kalinoski A, Willey J, Erhardt P, Lee J, et al: BIRC5 is a target for molecular imaging and detection of human pancreatic cancer. Cancer Lett 457: 10-19, 2019.

23. Schultz RM, Merriman RL, Toth JE, Zimmermann JE, Hertel LW, Andis SL, Dudley DE, Rutherford PG, Tanzer LR and Grindey GB: Evaluation of new anticancer agents against the MIA PaCa-2 and PANC-1 human pancreatic carcinoma xenografts. Oncol Res 5: 223-228, 1993.

24. Okada Y, Eibl G, Guha S, Duffy JP, Reber HA and Hines OJ: Nerve growth factor stimulates MMP-2 expression and activity and increases invasion by human pancreatic cancer cells. Clin Exp Metastasis 21: 285-292, 2004.

25. McGlynn KA, Hagberg K, Chen J, Graubard BI, London WT, Jick S and Sahasrabuddhe VV: Statin use and risk of primary liver cancer in the clinical practice research datalink. J Natl Cancer Inst 107: djv009, 2015.

26. Yu O, Eberg M, Benayoun S, Aprikian A, Batist G, Suissa S and Azoulay L: Use of statins and the risk of death in patients with prostate cancer. J Clin Oncol 32: 5-11, 2014.

27. Murtola TJ, Visvanathan K, Artama M, Vainio H and Pukkala E: Statin use and breast cancer survival: A nationwide cohort study from Finland. PLoS One 9: e110231, 2014.

28. Paškevičiūtė $M$ and Petrikaitè V: Differences of statin activity in 2D and 3D pancreatic cancer cell cultures. Drug Des Devel Ther 11: 3273-3280, 2017.

29. Ghaneh P, Costello E and Neoptolemos JP: Biology and management of pancreatic cancer. Gut 56: 1134-1152, 2007.

30. Archibugi L, Arcidiacono PG and Capurso G: Statin use is associated to a reduced risk of pancreatic cancer: A meta-analysis. Dig Liver Dis 51: 28-37, 2019.

31. Jian-Yu E, Graber JM, Lu SE, Lin Y, Lu-Yao G and Tan XL: Effect of metformin and statin use on survival in pancreatic cancer patients: A systematic literature review and meta-analysis. Curr Med Chem 25: 2595-2607, 2018.

32. Simon MS, Desai P, Wallace R, Wu C, Howard BV, Martin LW, Schlecht N, Liu S, Jay A, LeBlanc ES, et al: Prospective analysis of association between statins and pancreatic cancer risk in the Women's Health Initiative. Cancer Causes Control 27: 415-423, 2016. 
33. Lee HS, Lee SH, Lee HJ, Chung MJ, Park JY, Park SW, Song SY and Bang S: Statin use and its impact on survival in pancreatic cancer patients. Medicine (Baltimore) 95: e3607, 2016.

34. Wu BU, Chang J, Jeon CY, Pandol SJ, Huang B, Ngor EW, Difronzo AL and Cooper RM: Impact of statin use on survival in patients undergoing resection for early-stage pancreatic cancer. Am J Gastroenterol 110: 1233-1239, 2015.

35. Walker EJ, Ko AH, Holly EA and Bracci PM: Statin use and risk of pancreatic cancer: Results from a large, clinic-based case-control study. Cancer 121: 1287-1294, 2015.

36. Jeon CY, Pandol SJ, Wu B, Cook-Wiens G, Gottlieb RA, Merz CN and Goodman MT: The association of statin use after cancer diagnosis with survival in pancreatic cancer patients: A SEER-medicare analysis. PLoS One 10: e0121783, 2015.

37. Hong JY, Nam EM, Lee J, Park JO, Lee SC, Song SY, Choi SH, Heo JS, Park SH, Lim HY, et al: Randomized double-blinded, placebo-controlled phase II trial of simvastatin and gemcitabine in advanced pancreatic cancer patients. Cancer Chemother Pharmacol 73: 125-130, 2014.

38. Murai T: Cholesterol lowering: Role in cancer prevention and treatment. Biol Chem 396: 1-11, 2015.

39. Bahrami A, Parsamanesh N, Atkin SL, Banach M and Sahebkar A: Effect of statins on toll-like receptors: A new insight to pleiotropic effects. Pharmacol Res 135: 230-238, 2018.

40. Wu F, Luo T, Mei Y, Liu H, Dong J, Fang Y, Peng J and Guo Y: Simvastatin alters M1/M2 polarization of murine BV2 microglia via Notch signaling. J Neuroimmunol 316: 56-64, 2018.

41. Zacharek A, Chen J, Cui X, Yang Y and Chopp M: Simvastatin increases notch signaling activity and promotes arteriogenesis after stroke. Stroke 40: 254-260, 2009.
42. Verhulst A, D'Haese PC and De Broe ME: Inhibitors of HMG-CoA reductase reduce receptor-mediated endocytosis in human kidney proximal tubular cells. J Am Soc Nephrol 15: 2249-2257, 2004

43. Sidaway JE, Davidson RG, McTaggart F, Orton TC, Scott RC, Smith GJ and Brunskill NJ: Inhibitors of 3-hydroxy-3-methylglutaryl-CoA reductase reduce receptor-mediated endocytosis in opossum kidney cells. J Am Soc Nephrol 15: 2258-2265, 2004.

44. Jain RK: Barriers to drug delivery in solid tumors. Sci Am 271: 58-65, 1994.

45. DeGorter MK, Tirona RG, Schwarz UI, Choi YH, Dresser GK, Suskin N, Myers K, Zou G, Iwuchukwu O, Wei WQ, et al: Clinical and pharmacogenetic predictors of circulating atorvastatin and rosuvastatin concentrations in routine clinical care. Circ Cardiovasc Genet 6: 400-408, 2013.

46. Qin C, Yang G, Yang J, Ren B, Wang H, Chen G, Zhao F, You L, Wang $\mathrm{W}$ and Zhao Y: Metabolism of pancreatic cancer: Paving the way to better anticancer strategies. Mol Cancer 19: 50, 2020.

47. Sousa CM and Kimmelman AC: The complex landscape of pancreatic cancer metabolism. Carcinogenesis 35: 1441-1450, 2014.

48. Biancur DE and Kimmelman AC: The plasticity of pancreatic cancer metabolism in tumor progression and therapeutic resistance. Biochim Biophys Acta Rev Cancer 1870: 67-75, 2018.

49. Hermann PC and Sainz B Jr: Pancreatic cancer stem cells: A state or an entity? Semin Cancer Biol 53: 223-231, 2018.

50. New $M$ and Tooze S: The role of autophagy in pancreatic cancer-recent advances. Biology (Basel) 9: 7, 2019.

(i) $\ominus$ This work is licensed under a Creative Commons Attribution-NonCommercial-NoDerivatives 4.0 International (CC BY-NC-ND 4.0) License. 